\title{
Os desafios da construção da gestão participativa na universidade
}

\section{The challenges in the participatory management construction at university}

\author{
Andrea do Rocio Caldas* \\ Deise Cristina de Lima Picanço*
}

\begin{abstract}
RESUMO
O artigo busca delinear a trajetória na gestão do Setor de Educação da UFPR, no período de 2010 a 2014, quando as autoras estiveram à frente da direção setorial, buscando indicar os desafios da construção de bases mais participativas na gestão acadêmica. Aborda o processo de implantação do modelo de orçamento participativo e da rediscussão do projeto institucional e articulação de diversas ações que buscaram envolver a comunidade educacional interna e externa ao Setor e à Universidade. Entre as ações que serão abordadas, merecem destaque a criação de uma metodologia de orçamento participativo, a revisão do Planejamento Institucional, a criação de um evento permanente que pensasse a docência para além das práticas formativas universitárias, a criação de uma instância de articulação do Setor de Educação com as coordenações dos cursos de licenciatura e por fim a elaboração de uma proposta de qualificação e participação efetiva dos técnicos-administrativos, entre outras. Procura deslindar os impasses presentes na cultura enraizada de uma instituição calcada nos moldes da estrutura legada pela ditadura militar e as potencialidades advindas dos novos processos democratização.
\end{abstract}

Palavras-chave: Gestão educacional. Universidade. Democracia. Participação.

\footnotetext{
ABSTRACT

This article aims at presenting the management trajectory in the Education Sector at Federal University of Paraná - UFPR, Brazil, from 2010 to 2014,

*Universidade Federal do Paraná. Programa de Pós-graduação em Educação. Curitiba, Paraná, Brasil. E-mail: andreacaldas2011@gmail.com. https://orcid.org/0000-0002-3585-6816. E-mail: deisepicanco@gmail.com. https://orcid.org/0000-0002-2234-2090.
} 
when the authors were ahead the sector direction, indicating the challenges of more participatory bases construction at the academic management. It addresses the implementation of a participatory budget model and the institutional project rediscussion process and the articulation of several actions that aimed at involving the internal and the external educational community at the Sector and at the University. Among the actions to be discussed, some deserve to be highlighted: the creation of a participatory budget methodology, the review of the Institutional Planning, the creation of a permanent event to reflect on teaching beyond the university training practices, the creation of an articulation instance between the Education Sector and the coordination centers of the teaching undergraduate courses and finally the elaboration of an effective administrative technicians' qualification and participation proposal, among others. It aims at uncover the obstacles present in the rooted culture of an institution based on the molds of a structure inherited from the military dictatorship and the potentialities originated in the new democratization processes.

Keywords: Educational management. University. Democracy. Participation.

\section{O processo de escolha nas eleições internas na UFPR e no Setor de Educação}

A história da construção democrática em nosso país se reflete nas práticas internas das mais diversas instituições e espaços sociais assim como se entrecruza com elementos próprios da cultura e do ethos específico de cada um destes espaços.

No caso da universidade, a luta pela democracia se associou às lutas sociais pela expansão da oferta, bem como às lutas internas das corporações pela ampliação de direitos. Tais movimentos, contudo, albergaram embates com a herança elitista e a força do pensamento meritocrático ainda fortemente presentes neste espaço.

Como um dos pilares deste processo de democratização, a escolha dos dirigentes universitários foi e ainda é motivo de intenso debate no interior destas instituições, dialogando ou divergindo com as diferentes concepções de universidade e sociedade.

Ainda nos anos 80, no final da ditadura civil-militar, os movimentos organizados na universidade lograram conquistar, politicamente, o processo de consulta à comunidade para a escolha dos reitores, que pela lei da reforma universitária de 68 era prerrogativa do governo federal, a partir de elaboração de lista sêxtu- 
pla pelo Conselho Universitário. Esta importante conquista política, entretanto, não redundou em mudança do arcabouço legal, fazendo com que, a cada novo processo de "eleição" interna, as forças políticas se organizassem para garantir aquela conquista da comunidade universitária na escolha de seus dirigentes. É preciso assinalar que, no caso da educação básica, os resultados deste embate político em muitas unidades da federação foram mais auspiciosos, consagrando em instrumentos legais, o processo de escolha direta dos dirigentes escolares.

No período da redemocratização do país, o presidente Fernando Henrique Cardoso, antigo quadro da academia, edita a Lei 9192/95, que altera o processo de escolha dos dirigentes universitários e dita o seguinte:

Art. $1^{\circ} \mathrm{O}$ art. 16 da Lei n. ${ }^{\circ} 5.540$, de 28 de novembro de 1968 , com as alterações introduzidas pela Lei n. ${ }^{\circ} 6.420$, de 3 de junho de 1977 , e pela Lei n. ${ }^{\circ}$ 7.177, de 19 de dezembro de 1983, passa a vigorar com a seguinte redação:

Art. 16. A nomeação de Reitores e Vice-Reitores de universidades, e de Diretores e Vice-Diretores de unidades universitárias e de estabelecimentos isolados de ensino superior obedecerá ao seguinte:

I - o Reitor e Vice-Reitor de universidade federal serão nomeados pelo Presidente da República e escolhidos entre professores dos dois níveis mais elevados da Câmara ou que possuam título de doutor, cujos nomes figurem em listas tríplices organizadas pelo respectivo colegiado máximo, ou outro colegiado que o englobe, instituído especificamente para este fim, sendo a votação uninominal;

II - os colegiados a que se refere o inciso anterior, constituídos de representantes dos diversos segmentos da comunidade universitária e da sociedade, observarão o mínimo de setenta por cento de membros do corpo docente no total de sua composição;

III - em caso de consulta prévia à comunidade universitária, nos termos estabelecidos pelo colegiado máximo da instituição, prevalecerão a votação uninominal e o peso de setenta por cento para a manifestação do pessoal docente em relação à das demais categorias;

IV - os Diretores de unidades universitárias federais serão nomeados pelo Reitor, observados os mesmos procedimentos dos incisos anteriores (BRASIL, 1995).

Sendo assim, a dilatação democrática proposta pelo governo federal eleito substituiu a lista sêxtupla da ditadura pela lista tríplice e estabeleceu que, caso a consulta à comunidade universitária fosse realizada, a mesma deveria observar o peso sobreposto de $70 \%$ do corpo docente sobre os demais segmentos da comunidade universitária não abrindo mão, contudo, da escolha final dos reitores pela Presidência da República. Ainda que esta sobrevalorização do peso docente 
encontre apoio interno de alguns segmentos nas universidades, de modo geral, os processos de mobilização interna acabaram conquistando, na maioria das instituições - de maneira informal - a realização de processos de consulta garantindo paridade de pesos entre os docentes, técnicos-administrativos e estudantes.

Durante os governos Lula e Dilma tal lei não foi alterada, mantendo-se a lista tríplice e a escolha por parte do governo federal. Contudo, na criação dos Institutos Federais se adotou outra forma de organização, incorporando a eleição direta dos dirigentes. Assim é que, para os Institutos Federais, o Decreto 6986/09 define:

Art. $1^{\circ}$ Os Institutos Federais de Educação, Ciência e Tecnologia, criados pela Lei no 11.892, de 29 de dezembro de 2008, serão dirigidos por um Reitor, nomeado pelo Presidente da República, a partir da indicação feita pela comunidade escolar, de acordo com o disposto neste Decreto.

Parágrafo único. Os campi que integram cada Instituto Federal de Educação, Ciência e Tecnologia serão dirigidos por Diretores-Gerais nomeados pelo Reitor, após processo de consulta à comunidade respectiva. [...]

Art. $9^{\circ}$ Todos os servidores que compõem o Quadro de Pessoal Ativo Permanente da Instituição, bem como os alunos regularmente matriculados nos cursos de ensino médio, técnico, de graduação e de pós-graduação, presenciais ou a distância, participarão do processo de consulta a que se refere o art. $2^{\circ}$, de acordo com a legislação pertinente.[...]

$\S 2{ }^{\circ}$ Os Institutos de Educação, Ciência e Tecnologia deverão proporcionar aos alunos matriculados em cursos oferecidos na modalidade de educação a distância, condições idênticas às oferecidas aos alunos de cursos presenciais, para fins de participação no processo de consulta.

Art. 10. O processo de consulta será finalizado com a escolha de um único candidato para cada cargo, considerando-se o peso da participação de cada segmento representado, de acordo com o disposto no art. $9^{\circ}$, em relação ao total do universo consultado (BRASIL, 2009).

Destarte, vivemos hoje, na esfera da educação federal pública, duas realidades bastante distintas no campo da regulação da escolha de dirigentes, a primeira dirigida às universidades que mantém a lista tríplice - cuja escolha do primeiro mais votado pode ou não ocorrer por parte do Presidente da República - e o peso de setenta por cento dos docentes nos processos formais e a outra dirigida aos Institutos Federais, com parâmetros mais precisos nas consultas internas, para toda a rede e para todos os pleitos.

No caso das universidades, dado à limitação do arcabouço legal, a consulta à comunidade - que se mantém informal - tem se erigido, na maior parte das vezes, a partir de processos de negociações internas que a cada pleito eleitoral, 
a depender do cenário e da correlação de forças, estabelecem as regras, pesos e universo eleitoral.

Assim, as universidades que forjaram, historicamente, os processos de consulta paritária aos segmentos da comunidade universitária têm operado informal e politicamente numa negociação entre o texto da lei e o contexto real. Tal terreno movediço acabou, muitas vezes, dando margem a mudanças de colégio eleitoral e peso de cada categoria, não só a cada eleição, mas em cada unidade local interna dentro da universidade.

A Universidade Federal do Paraná (UFPR) realizou sua primeira consulta à comunidade para escolha de reitor no ano de 1986. Tal processo acompanhava o movimento de redemocratização do país que clamava por mudanças nas instituições. Desde o início, na UFPR, estabeleceu-se que o processo de consulta seria conduzido pelas entidades representativas dos docentes, estudantes e técnicos e que tal resultado seria submetido ao Colégio Eleitoral (Conselho Universitário e Conselho de Curadores) para o cumprimento da legislação que indicava a necessidade de elaboração de uma lista sêxtupla a ser encaminhada ao governo federal. Este acordo político se manteve inalterado até então, havendo um compromisso interno de que o resultado da consulta seria respeitado e que os demais candidatos que não lograram vitória eleitoral renunciaram à postulação, para evitar riscos de que o nomeado pela Presidência da República não fosse, de fato, o mais votado. Desde o início, também, foi pactuada a paridade de terços nos pesos das categorias internas.

No caso dos Setores - denominação adotada pela UFPR para o equivalente a Centros ou Faculdades - também passaram a ocorrer consultas internas, de modo geral seguindo as mesmas regras, para a escolha de seus (suas) diretores (as). No Setor de Educação se adotou a proporção não de um terço para cada categoria, mas de cinquenta por cento para docentes e técnicos e cinquenta por cento para estudantes. Muito provavelmente, esta fórmula - que aumenta o peso da participação estudantil - seguiu a influência da rede pública de educação básica que, na mesma época, no Paraná, conquistou legalmente o instituto de eleição para os (as) diretores (as) escolares.

Na construção desta dinâmica interna alguns procedimentos passaram a conformar uma nova cultura de gestão interna, incluindo debates de programas, apresentação pública de chapas e garantia da realização periódica dos processos de consultas.

Neste artigo, pretendemos descrever como estes elementos estiveram presentes no processo de eleição e construção da gestão para a direção do Setor de Educação, no período de 2010 a 2014. 


\section{Um projeto de gestão democrático, plural e participativo.}

Se o estabelecimento do instituto da eleição para escolha dos gestores é a forma mais democrática, uma vez que incorpora todos os segmentos da comunidade escolar, a sua realização não garante que a gestão escolhida será necessariamente pautada por procedimentos democráticos.

De modo geral, seja no país ou nas mais variadas instituições, o que se percebe é uma permanência da democracia quase cartorial, onde o momento do voto resume a participação da cidadania. No caso da universidade, e especificamente a UFPR, o fato de poucas alterações teriam ocorrido nos regimentos e estatutos internos, agrava a probabilidade de centralização de poder nas mãos dos dirigentes ou nos colegiados, hegemonizados pelos docentes. Nesta direção, a preocupação central do grupo que se reuniu para elaborar o programa de gestão, que acabou vencendo a eleição do Setor de Educação, em 2010, é que o processo de democratização e participação deveria se iniciar na campanha e permanecer após as eleições.

A primeira definição, que ocorreu em uma reunião aberta, foi acerca dos princípios norteadores que acabaram indicando o nome da chapa e os eixos programáticos. Somente após esta discussão inicial é que os nomes para direção e vice direção foram escolhidos. Em seguida, foram realizadas várias reuniões temáticas, incluindo também docentes e estudantes dos cursos de licenciatura, atendidos pelo Setor de Educação, ainda que estes não fizessem parte do colégio eleitoral desta eleição setorial. A interação ocorreu também com a criação de um blog (http://andreadeise.blogspot.com/2010/) e com a realização de vários debates entre as duas chapas concorrentes, com ampla participação da comunidade e transmissão via Youtube ${ }^{\mathrm{TM}}$. O programa construído neste processo participativo de debates ficou disponível no blog e foi compartilhado em material impresso, na visita às salas de aula, gabinetes e reuniões abertas.

Como se assinalou anteriormente, a chapa denominada Democracia, Participação, Pluralidade e Diversidade assumiu como núcleo essencial programático a democratização da gestão e a consolidação de processos mais permanentes e orgânicos de tomada de decisões coletivas e compartilhadas. Seu programa destaca que:

O Setor de Educação tem uma longa e bela história na defesa e construção da Educação Pública, Gratuita e de Qualidade. História esta feita pelos seus professores, técnicos e alunos de graduação e pós-graduação. É preciso, todavia, redefinir a sua política acadêmica e institucional a 
partir dos princípios da democracia, da diversidade e da transparência, o que significa democratizar as decisões, mas também o acesso aos meios, aos procedimentos e aos conteúdos de nossas ações, além de defender a ampliação dos espaços de decisão, debate e representação política dentro e fora do próprio Setor. Foi com esse compromisso que a Chapa Democracia, liderada pelas professoras Andréa Caldas e Deise Picanço deflagrou, no início deste ano, um processo de discussão e construção coletiva de um projeto de gestão para o Setor de Educação, para o período de 2010 a 2014, envolvendo toda a comunidade setorial, além de nossos pares dos cursos de licenciatura (BLOG DE CAMPANHA, 2010).

Em seguida, são descritos os princípios gerais, quais sejam, redefinição das políticas do Setor a partir dos princípios da diversidade e da transparência, o que significa democratizar ações/decisões, meios, procedimentos e conteúdos e ampliar os espaços de decisão, debate e representação política. E por fim, o programa, subdivido em temáticas, incluindo questões mais amplas da política institucional e outras, bem específicas, dizendo respeito à tomada de decisões e procedimentos administrativos é apresentado:

\section{PRINCÍPIOS}

\section{Democratização e ampliação dos espaços de decisão e representação política:}

- Garantir amplo espaço para o debate nos vários colegiados e unidades que compõem o Setor.

- Ampliar e fortalecer as formas de gestão democráticas, colegiadas, participativas e autônomas.

- Garantir e valorizar as representações em órgãos colegiados internos e superiores (CEPE, COPLAD, COUN, Fóruns de Coordenadores, etc), bem como nas pró-reitorias.

\section{Democratização das ações, dos meios e procedimentos:}

- Estabelecer critérios universais, objetivos e transparentes na distribuição de recursos, aumentando a autonomia dos departamentos e unidades do Setor.

- Estabelecer critérios universais, objetivos e transparentes na gestão de processos institucionais (de órgãos colegiados; de docentes, estudantes e técnicos; de projetos institucionais).

- Garantir o funcionamento das unidades do Setor, respeitando a diversidade e especificidade de cada uma delas e melhorando as condições físicas, humanas e acadêmicas. 


\section{Transparência e visibilidade do Setor:}

- Estabelecer política de acesso à informação, utilizando de vários meios eletrônicos e impressos.

- Garantir o acesso da comunidade acadêmica aos documentos gerados e aprovados nos órgãos colegiados como atas, projetos, relatórios, ementário das disciplinas dos cursos de graduação e pós-graduação (stricto e latu senso).

- Tornar pública a gestão financeira do Setor de Educação.

- Garantir a representatividade do Setor, por meio da qualidade de sua participação e da sua produção de conhecimento, nas diversas instâncias da UFPR e externas.

- Atuar permanentemente para estabelecer um Sistema Nacional Articulado de Educação, levando a termo proposições do Plano Nacional de Educação.

\section{Diversidade}

- Reconhecimento da justiça social, igualdade, diversidade e inclusão como objetivos permanentes das políticas educacionais e agenda social, buscando respostas públicas e democráticas.

- Estabelecer diálogo constante e consistente com movimentos sociais e movimentos de trabalhadores em educação, em prol de políticas articuladas com os princípios e ações promotoras de diversidade/direito à diferença e igualdade; desenvolvimento de políticas afirmativas de combate às desigualdades.

\section{AÇÕES:}

\section{Representações, instâncias decisórias e de convivência}

- Realização sistemática de assembléias setoriais que possibilitem que a tomada de decisões integre todos os segmentos.

- Discussão coletiva e democrática das prioridades orçamentárias;

- Estabelecer um canal de comunicação mais efetivo entre a comunidade setorial e a direção do Setor de Educação;

- Espaço de convivência que possibilite a integração de toda a comunidade setorial;

- Oportunizar espaços de difusão cultural no Setor;

\section{Visibilidade das ações, informações e rotinas do Setor}

- Criação de mecanismos que possibilitem dar visibilidade às atribuições dos técnicos/as e gestores, assim como isonomia de tratamento;

- Planejamento das rotinas administrativas como compras, recomposição de materiais e manutenção, integrada ao calendário da UFPR e às prioridades pedagógicas do Setor; 
- Aperfeiçoamento do site do Setor como ferramenta de comunicação e distribuição da informação;

- Melhoria da comunicação interna do Setor, com visibilidade das normatizações e orientações para os professores/as, estudantes e técnicos/as;

- Garantia de autonomia e apoio técnico para gestão acadêmica de projetos e recursos, sem ingerência da direção do Setor;

- Publicizar horários de trabalho de professores/as, técnicos/as e gestores, assim como do ensalamento, com a respectiva divulgação na página do Setor;

\section{Ampliação e qualificação dos quadros}

- Reposição e ampliação do quadro técnico-adminstrativo do Setor;

- Desenvolver e garantir uma política coletiva de qualificação para professores/ as e técnicos/as do Setor;

- Criação de uma estrutura de apoio permanente à realização dos eventos para planejamento, divulgação através de página específica e atualizada, realização de inscrições on-line, impressão de certificados (por exemplo, através dos serviços da Imprensa da UFPR) e entrega dos mesmos durante o evento, etc;

- Apoio e fomento aos cursos de Especialização, com garantia de espaço físico e recursos;

- Garantia de técnicos para o CEAPE e para o CEPED como forma de auxiliar a gestão de projetos;

- Profissionalização dos procedimentos administrativos incorporando os avanços tecnológicos disponíveis (por exemplo, leitora de código de barras para o controle do patrimônio, fechaduras eletrônicas, etc);

\section{Espaço físico e infraestrutura}

- Melhoria da estrutura física e realização de estudo da ocupação do espaço físico do Setor nos Edifícios D. Pedro I e D. Pedro II, com vistas a melhorias e adequações;

- Elaboração coletiva e acompanhamento de projeto de ocupação do campus Rebouças, a partir de discussão do Projeto Pedagógico do Setor;

- Garantia de condições físicas adequadas, tais como, bebedouros, limpeza das salas e instalações sanitárias;

- Avaliar junto aos técnicos e gestores a atual situação do uso de cópias de chaves das salas e criar um mecanismo de monitoramento destas cópias para garantir o bom funcionamento dos espaços, com segurança e facilidade de acesso;

- Resolução da questão do acesso e uso dos banheiros;

- Revisão dos atuais procedimentos de uso dos equipamentos;

- Rever a questão das fotocópias no Setor; 
$\mathrm{O}$ rico processo de construção e debate mobilizou intensamente a comunidade interna, e incluiu também a publicação de manifestos de apoio da sociedade civil - sindicatos, movimentos sociais - e de colegas de outras instituições de ensino superior.

\section{Por uma metodologia de orçamento participativo e a constru- ção de uma nova cultura interna}

Um dos pontos centrais não só do programa, mas das polêmicas que constaram dos debates nesta eleição setorial foi a forma de organização do orçamento interno e o processo de tomada de decisões.

Como já indicado, ainda que tenha havido um processo de redemocratização da universidade, há ainda muitas permanências estruturais que datam da Reforma Universitária de 68, e outras que, embora modificadas, ainda nucleiam as decisões em torno dos dirigentes centrais.

No caso específico do orçamento do Setor de Educação, não obstante, a programação orçamentária fosse apresentada ao Conselho Setorial, bem como sua prestação de contas, a tomada de decisões que envolvia compras, destinações de diárias e passagens, apoio a eventos, ajuda estudantil acabava, no cotidiano, passando pela decisão estrita da direção de Setor. E quando havia consultas, de modo geral, elas se circunscreviam a itens específicos de compras de pregão, ou a uma destinação de um quantum de recursos para os departamentos. Desta forma, a decisão da nossa chapa de apresentar, na campanha, o detalhamento do orçamento do Setor e a descrição das despesas realizadas movimentou o debate na comunidade setorial sobre o processo de tomada de decisões e planejamento orçamentário.

Uma das primeiras medidas adotadas pela gestão eleita, e que tomou posse no final de setembro, foi a realização de uma assembleia setorial, precedida de debates nos departamentos, entre os estudantes e técnicos para definição do orçamento ainda a ser empenhado naquele ano, que representava mais de $60 \%$ daquele ano e o orçamento do ano seguinte.

Esta nova prática, batizada de orçamento participativo, acabou gerando certas inquietações, no início, que dizia respeito à paridade de votos na assembleia e uma possível prevalência quantitativa em detrimento da proporcionalidade setorial e mesmo ao questionamento da assembleia como espaço de decisão do orçamento. Contudo, assegurando-se que os debates prévios dos departamentos e categorias seriam levados em conta, que o 
Conselho Setorial homologaria oficialmente as decisões e que haveria plena transparência (inclusive na página oficial do Setor) das decisões aprovadas e a subsequente prestação de contas, este processo acabou sendo incorporado à cultura interna do Setor. Ademais, revelou-se extremamente pedagógico, considerando que informações a respeito do orçamento público, do funcionamento de pregões, da repartição de recursos e rubricas passaram a ser partilhadas por toda a comunidade setorial. As eventuais divergências sobre solicitações que extrapolavam o orçamento eram debatidas publicamente, construindo consensos, não sendo necessário até o presente momento ter havido nenhuma disputa através de voto.

Se para alguns este mecanismo de discussão do planejamento orçamentário poderia significar uma diminuição do poder do diretor(a) de Setor - nominado estatutariamente como ordenador de despesas -, em nossa avaliação tal processo ajudou a construir a legitimidade das decisões tomadas, especialmente em tempos de redução orçamentária, de vez que a definição das prioridades foi assumida coletivamente.

Do ponto de vista administrativo, este procedimento - com calendário regular de debates - permitiu a organização do planejamento anual de compras, o que garantiu que o Setor empenhasse a totalidade dos recursos em todos os anos. A par disto, foram definidos critérios para a destinação de passagens e diárias, distribuição de recursos entre os departamentos e auxilio estudantil.

Contudo, curiosamente, pudemos observar que as assembleias para o orçamento participativo tiveram, paulatinamente, a redução do número de participantes, tendo em alguns casos quase que apenas os "representantes" das categorias. Ou seja, o espaço da chamada democracia direta acabou incorporando, pela própria dinâmica histórica, a lógica da democracia representativa.

Em nossa avaliação isto não reduz a importância e a vitalidade deste movimento, uma vez que a possibilidade de que todos participassem esteve sempre dada e acabou sendo incorporada como prática permanente, inclusive com normatização no regimento setorial.

Mais do que uma proposta de uma gestão, o orçamento participativo e a transparência não só na prestação de contas, mas na tomada de decisões passou a fazer parte da cultura institucional do Setor de Educação da UFPR. 


\section{A construção de uma prática participativa no planejamento institucional e nas políticas de articulação com unidades, órgãos públicos e movimentos sociais.}

Ainda com o propósito de instituir processos mais orgânicos de gestão, a partir da construção coletiva de um projeto propositivo para as ações pedagógicas e institucionais, e suas derivações administrativas e financeiras, o ano de 2011 se iniciou com a proposição da Semana de Planejamento, em que foram realizadas sessões temáticas por meio de convites dirigidos a toda a comunidade setorial no intuito de avançar na sistematização do diagnóstico e metas para a Graduação, Pós-graduação, Pesquisa e Extensão no Setor. Em reunião do Conselho Setorial de 17 de fevereiro de 2011, defendeu-se que a ideia não era suprimir os espaços de planejamento dos departamentos e áreas, mas propor que o Setor refletisse sobre metas institucionais para as atividades fins: formação inicial e continuada de professores e pedagogos, pesquisa e extensão. Assim, a distribuição das reflexões por Grupos de Trabalho (GTs) ficou assim definida: GT Pedagogia (Pedagogia EaD e Presencial); GT Pós-graduação (Especializações, Programas de Mestrado e Doutorado) - naquela ocasião ainda não estava implementado o Programa de Mestrado Profissional, por isso foi mencionado como projeto de curso; GT Extensão, organizado pelo Centro de Assessoramento Pedagógico - CEAPE; GT Pesquisa, organizado pelo Centro de Estudos e Pesquisas Educacionais - CEPED; GT para as Licenciaturas; e GT para Gestão. Cada GT deveria realizar uma primeira reunião para elaboração de diagnóstico preliminar e proposição de metodologia de trabalho para definição de metas, para que estes GTs se tornassem permanentes. Essa mesma metodologia foi realizada durante os anos de 2012 e 2013. Após cada período inicial os GTs enviaram planilhas e/ou textos com o diagnóstico de cada área, que posteriormente eram sistematizados e formatados para serem apresentados a toda a comunidade, para apreciação e conhecimento, em plenária setorial aberta. A seguir apresentamos algumas considerações sobre os trabalhos de cada GT.

O GT de Pedagogia, além de fazer um diagnóstico das necessidades de revisão dos Projetos Político-Pedagógicos dos Cursos (PPCs), elaborou um diagnóstico das suas condições de funcionamento, desde o acervo da Biblioteca de Ciências Humanas e Educação, até a regulamentação dos Trabalhos de Conclusão de Curso e uma avaliação do funcionamento dos campos de estágio e a relação com as Secretarias de Educação do Estado e do Município. Analisou também as necessidades financeiras e administrativas apresentando metas e propostas.

O GT de Pós-Graduação apresentou de forma sucinta as demandas admi- 
nistrativas e financeiras, além de algumas metas bastante objetivas. O GT de Pesquisa apresentou dados bastante detalhados sobre os pesquisadores do Setor e sua atuação vinculada ou não aos programas de financiamento como PIBIC e IC/TN. O diagnóstico orientou as proposições que sugeriam maior circulação de informações e a criação de espaços para pesquisa, como laboratórios e núcleos. Estas ações foram direcionadas ao projeto de ocupação do novo campus da Universidade, instalado no ano de 2018, denominado Campus Rebouças. O GT Extensão também apresentou diagnóstico detalhado e algumas proposições, como maior articulação entre as ações, em especial com as secretarias municipais de educação.

Por fim, o GT de gestão sistematizou as demandas dos demais GTs que foram aprovadas em plenária setorial aberta e encaminhou ao Conselho Setorial. Por fim, devido sua importância na articulação das atividades formativas de graduação no Setor, sobre o GT de licenciaturas discorreremos detalhadamente a seguir.

Sobre a participação da comunidade setorial nos Grupos de trabalho temáticos, avaliamos que, naquele momento, a adesão às reuniões não era equânime em todas as áreas. Se nas reuniões sobre os cursos de Pedagogia EaD e Presencial houve maior número de participantes, entre docentes, técnicos-administrativos e estudantes, nos GTs sobre pós-graduação e extensão o número de participantes era muito reduzido, limitando -se à participação de alguns docentes e dos técnicos administrativos ligados às unidades responsáveis, como CEPED e CEAPE. Ao apresentar o texto de sistematização, em 2013, avaliou-se que "ainda que a maior parte destas reuniões tenha contado com pequena participação, o que em si nos traz a necessidade de refletirmos sobre o entendimento que temos do projeto de formação do Setor de Educação e da própria concepção de planejamento e gestão, compreendemos que se trata do movimento real e possível de construção coletiva até aqui “empreendido". Essa mesma metodologia dos GTs Temáticos foi mantida até 2013, pois em 2014, muitas demandas ainda estavam vigentes e esbarravam na necessidade de revisão do Regimento do Setor de Educação (que será apresentado em seguida). Por conta disso, a metodologia de planejamento anual por meio dos GTs foi substituída por um debate mais direcionado ao novo Regimento e novamente os departamentos assumiram a tarefa de fazer o levantamento das demandas anuais. No entanto, algumas unidades mantiveram a prática de planejamento coletivo, como o GT de Licenciaturas, que se transformou em Centro de Articulação, e o colegiado

1 Planejamento Institucional. Texto publicado na página oficial do Setor de educação. Disponível em: http://www.educacao.ufpr.br/portal/wp-content/uploads/2013/03/projeto-institucional-pos-revisao.pdf. Acesso em: 19 dez. 2018. 
do Curso de Pedagogia presencial, que criou Comissões para acompanhamento dos TCCs e da implementação das reformulações curriculares.

De forma bastante distinta, o GT Licenciaturas se organizou em torno de um conjunto de proposições de gestão, ainda no período de campanha para as eleições. Nas Reuniões Temáticas ${ }^{2}$ foram levantadas algumas questões relativas à relação do Setor com as demais licenciaturas, já que apenas a licenciatura para Educação Infantil e Séries iniciais, vinculadas ao curso de Pedagogia, estão inteiramente no Setor de Educação. As demais licenciaturas são originárias das áreas específicas de conhecimento que, historicamente, têm a formação pedagógica nos departamentos do Setor de Educação.

A formação de professores na UFPR, assim como em muitas universidades, iniciou-se no final da década de 1930. Naquela época o Departamento de Pedagogia, que depois se transformou na Faculdade de Educação (1968) e depois no Setor de Educação (1973), ministrava o Curso de Didática, responsável "por licenciar professores das diversas áreas do conhecimento para atuarem principalmente no ensino secundário" . Consequentemente, essa formação foi historicamente construída como complementar à formação dada nas áreas de conhecimento específico. Para superar essa relação de complementariedade na formação do professor, que ficou conhecida até a década de 1990 como " $3+1$ ", ou seja, três anos de formação nas áreas específicas e um ano de formação pedagógica, muitas reformulações curriculares foram realizadas, sem que a relação do Setor com as coordenações de curso fosse modificada. Com esse propósito, as reuniões temáticas sobre as licenciaturas apontavam a necessidade de diversas ações, conforme consta no programa resultante das reuniões temáticas.

A primeira preocupação, expressa na proposta de criar um fórum permanente, teve inicio no dia 15 de outubro de 2010, no primeiro Dia D Educação, evento criado logo no início da gestão. Segundo reportagem divulgada na época, uma das pretensões do encontro era " "proporcionar a articulação e a integração do Setor de Educação com as comunidades interna e externa ${ }^{4}$ ' [...]". Para tanto, integrando o programa, os debates também contaram com "alguns diretores de setor, coordenadores de cursos, além de membros da sociedade

2 Para saber mais: http://andreadeise.blogspot.com/p/debates-tematicos.html.

3 Para maiores detalhes consultar o Memorial do Setor de Educação. Disponível em: http:// www.educacao.ufpr.br/portal/memorial/.

4 Reportagem publicada pelo portal da UFPR em 15 de outubro de 2010. Disponível em: http://www.ufpr.br/portalufpr/noticias/setor-de-educacao-comemora-o-dia-d-educacao/. Acesso em: 15 mai. 2019. 
civil como representantes do MST, das secretarias municipal e estadual da Educação, do Fórum em Defesa da Escola Pública e outros"s.

O Dia D Educação foi organizado pela direção do Setor e logo se consolidou como um evento de um dia, com palestras, mesas e apresentações culturais relacionadas ao tema da docência e da educação como um direito de todos. Seu principal propósito é resgatar o caráter reflexivo e propositivo por ocasião da celebração do Dia dos Professores, comemorado no dia 15 de outubro. Como esse dia não é feriado na UFPR, ao contrario de outras instituições de ensino, a intensão é celebrar a docência refletindo sobre suas conquistas e desafios. Hoje, o evento faz parte do calendário da UFPR e tem adesão de docentes e discentes de diversos cursos de licenciatura, e é organizado pelo Centro de Articulação das Licenciaturas - CEALI.

No primeiro Dia D Educação, em 2010, uma das mesas redondas, intitulada "Formação de Professores: múltiplos saberes", contou com a presença do Coordenador Institucional do PIBID/UFPR, professor Eduardo Barra, que tratou do importante resgate da profissão docente que o programa tem realizado em algumas áreas do conhecimento na UFPR. Também esteve presente o professor Marcio Guimarães, na época Coordenador do Curso de Letras, que reiterou a necessidade de maior articulação entre as áreas de formação. Por fim, a professora Rose M. Trojan, pesquisadora do Departamento de Planejamento Escolar, tratou da relação entre a formação de professores e o ensino superior na sociedade. Outra mesa, organizada para aquele evento, intitulada 'Educação e Diversidade: múltiplas faces', contou com a presença de pesquisadores e representantes do movimento negro, de diversidade sexual e de gênero, como a professora e pesquisadora Megg Rayara Gomes de Oliveira.

Entre outras questões, o evento trouxe para o debate uma antiga preocupação no campo da formação de professores que são os modelos de organização curricular, pautados ora por uma sobrevalorização da formação teórica, como conhecimento a ser adquirido, ora por uma sobrevalorização da prática, sob o risco de uma formação desprovida de reflexão sobre o processo de produção do conhecimento científico. Além disso, colocou a questão da diversidade como catalizadora de um processo que busca dar maior protagonismo aos sujeitos da educação na formulação do currículo escolar e nas reflexões sobre as práticas pedagógicas.

Em relação à preocupação com a "construção de espaços políticos e institucionais de defesa da licenciatura na UFPR" e "a relação entre os cursos,

5 Reportagem publicada pelo portal da UFPR em 15 de outubro de 2010. Disponível em: http://www.ufpr.br/portalufpr/noticias/setor-de-educacao-comemora-o-dia-d-educacao/. Acesso em: 15 mai. 2019. 
permitindo o intercâmbio mais efetivo de experiências formativas no ensino, na pesquisa e na extensão" a proposta inicial da direção foi a de fortalecer o Fórum das licenciaturas, lançado no Dia D Educação.

As ações em torno de um espaço institucional para articulação de políticas de formação de professores e trocas entre as licenciaturas iniciaram logo depois, no dia 18 de novembro de 2010. A abertura do VII Seminário de Teoria e Prática de Ensino - evento em que o foco são as trocas de experiências entre docentes e discentes sobre a prática de docência - contou com a presença da professora Selma Garrido Pimenta/USP, que proferiu uma conferência sobre "Formação de Professores: entrelaçamentos necessários". No dia seguinte, a professora participou, a convite do Fórum de Licenciaturas, de uma conversa sobre os estágios e a relação entre as áreas de formação nas licenciaturas. Nessa roda de conversa, com professores de práticas pedagógicas e de docência da UFPR, os professores representantes do Núcleo de Licenciaturas da PROGRAD, os coordenadores de curso de Licenciatura da UFPR e representantes da Coordenação Geral de Estágios da PROGRAD/UFPR, a professora Selma Garrido relatou um pouco sobre sua experiência como Pró-reitora de Graduação na USP e as tentativas de tornar os estágios espaços efetivos de formação inicial e continuada. Estiveram presentes alguns coordenadores de curso, docentes dos três departamentos do Setor de Educação, estudantes e professores da rede estadual de ensino, entre outros participantes do Seminário.

A preocupação do Fórum naquele momento era articular e mobilizar a discussão em torno de uma proposição de mudança normativa em relação aos estágios que tramitava no Conselho de Ensino Pesquisa e Extensão da UFPR. Esse debate foi acompanhado pelo Fórum de Licenciaturas, substituído pela Coordenação de Licenciaturas e posteriormente pelo CEALI, em especial pelos professores Altair Pivovar (do Setor de Educação) e Alexandre Trovon (do Departamento de Matemática, e vice-diretor do Setor de Exatas). Essa tramitação resultou na aprovação, em 2017, de uma resolução que regulamenta o Estágio em Formação de Professores - EFP, que garante a supervisão direta dos docentes na Educação Básica e no Ensino Profissional ${ }^{6}$.

Após ser criado, no início de 2011, e para dar continuidade e sistematicidade aos trabalhos promovidos pelo Fórum, o GT de Licenciaturas, realizou reuniões durante e após a Semana de Planejamento, conforme já mencionado. Para a retomada dos debates, foi realizada no dia 06 de junho nova reunião em que foram indicados alguns temas importantes para serem discutidos em reuniões mensais em calendário a ser aprovado no Fórum de Planejamento:

6 UFPR. Resolução no 35/17-CEPE. Disponível em: http://www.soc.ufpr.br/portal/wp-content/uploads/2017/12/cepe3517assinada.pdf. Acesso em: 19 dez. 2018. 
orientação e supervisão de estágios dentro da resolução CEPE 46/10; identidade da licenciatura frente ao bacharelado na formação do professor; avaliação da aprendizagem. Essa reunião teve um caráter preparatório para o encontro de Graduação do Fórum de Planejamento - que aconteceria durante a SEPE (Seminário de Ensino Pesquisa e Extensão do Setor de Educação). Durante este evento, após discussão geral, especificamente sobre as licenciaturas, foram sugeridas quatro reuniões com os seguintes temas: identidade das licenciaturas; estágio na formação de professores; avaliação da aprendizagem; Dia D Educação: síntese e definição de metas.

Nos meses seguintes, o calendário sofreu algumas alterações, e o debate foi retomado no dia 19 de setembro de 2011 com o tema "Licenciatura: identidade, contradições e metas". No dia 24 de outubro de 2011, foi realizado o segundo Dia D Educação, com uma mesa sobre "Formação de professores: múltiplos saberes", ainda sob a coordenação da direção.

Após a aprovação da Coordenação das Licenciaturas em Conselho Setorial, no dia 19 de outubro de 2011, passou-se a debater sobre a formulação do seu Regimento, com representantes de diferentes coordenações de curso. Nessas reuniões, defendeu-se o caráter plural nas representações do CEALI, por isso, o regimento, aprovado em reunião 14 de março de 2012, define que:

\section{Da composição}

Art. $5^{\circ} \mathrm{O}$ Centro de Articulação das Licenciaturas será presidido por um coordenador e um vice-coordenador indicados pelo conselho setorial e composto por:

a) um representante de cada área dos Departamentos do Setor de Educação e um suplente, indicados em Plenária Departamental;

b) representantes discentes dos cursos de licenciatura na proporção de 1/5 dos membros do Colegiado, indicados pelos Centros acadêmicos;

c) dois representantes da comunidade externa relacionados ao campo educacional (Fórum Estadual de Educação, APP Sindicato);

d) um representante técnico-administrativo do Setor de Educação (UFPR, 2012) $)^{7}$.

$\mathrm{Na}$ ata de aprovação consta que "comissão se reuniu e deliberou sobre a proposta de criação da Coordenação de Licenciatura que ora recebe o nome de Centro de Articulação das Licenciaturas do Setor de Educação".

7 Regimento do CEALI publicado na página do Setor de Educação. Disponível em: http:// www.educacao.ufpr.br/portal/sobre-o-ceali/. Acesso em: 19 dez. 2018.

8 Atas publicadas na página do Setor de Educação. Disponível em: http://www.educacao. ufpr.br/portal/conselho-setorial. Acesso em: 19 dez. 2018. 
No entanto, o CEALI foi oficialmente instaurado no terceiro Dia D Educação, no dia 16 de outubro de 2012. Esse evento, contou com uma mesa intitulada "Formação dos Profissionais da Educação: As Vozes da Escola", com Michele Jaremczyk, Representante do Conselho Municipal de Educação de Curitiba e egressa do Curso de Pedagogia - UFPR, Fabiano Stoiev, Professor Supervisor PIBID/UFPR e Tania Lopes, representando o Fórum Permanente de Educação e Diversidade Étnico-Racial (FPEDER-PR). Houve também lançamento de livros e à noite aconteceu uma mesa sobre "O Novo Plano Nacional de Educação: Desafios e Perspectivas para a Escola e a Universidade", com a presença dos(as) professores(as) Paulo Vinicius Baptista da Silva, Coordenador do Programa de Pós-Graduação em Educação/UFPR, Andrea do Rocio Caldas, Diretora do Setor de Educação/ UFPR, Ângelo Ricardo de Souza, Professor e Pesquisador do NUPE/UFPR, Francisco das Chagas Fernandes, Secretário Adjunto Executivo do MEC e Coordenador do Fórum Nacional de Educação e Zaki Akel Sobrinho, Reitor da UFPR e Coordenador do Fórum Estadual de Educação. Nos anos seguintes o CEALI e a direção do Setor de Educação organizaram juntos o Dia D Educação e lideraram diversos debates sobre formação de professores na UFPR.

Além da aprovação da nova modalidade de Estágio para Formação de Professores, o CEALI tem realizado inúmeras reuniões de orientação para as reformulações curriculares dos cursos de licenciatura, como a avaliação sobre a proposta da Residência Pedagógica e o novo PIBID, e tem participado de atividades organizadas pela Pró-Reitoria de Graduação. Em 2018, o CEALI organizou, no Dia D Educação, duas mesas com o tema "Reflexões sobre a Base Nacional Comum Curricular (BNCC) do Ensino Médio".

\section{O regimento setorial revisado: permanências e possíveis rupturas}

Além do compromisso com o debate em torno do projeto institucional do Setor, nossa gestão entendia ser fundamental que as proposições e as práticas, no que diz respeito às estruturas administrativas e de gestão fossem normatizadas.

Tal preocupação se acentuava com o fato do regimento interno do Setor datar de 1973, incorporando preceitos oriundos da reforma universitária que

9 Reportagem publicada na página oficial da UFPR. Disponível em: http://www.ufpr.br/ portalufpr/eventos/dia-d-educacao-reflete-sobre-a-base-nacional-comum-curricular-do-ensino-medio-15-de-outubro/. Acesso em: 19 dez. 2018. 
incluía entre outros aspectos, por exemplo, a possibilidade de "destituição do Centro Acadêmico por motivo de insubordinação" (sic).

Felizmente, a maturidade histórica e política fez com que o Setor avançasse e democratizasse suas práticas, não obstante o entulho legal. Da mesma forma, os avanços na legislação geral e as mudanças no estatuto da universidade ainda que não tenham sido expressivas - fazia com que muitos dispositivos do regimento setorial resultassem caducos ou sem efeito.

Ainda assim, especialmente por se tratar de um Setor que tem como objeto de estudo e de pesquisa a gestão educacional era fundamental que houvesse a construção de um regimento que representasse o projeto coletivo institucional. Não que esta mudança não tivesse sido intentada anteriormente. Muito ao contrário, ao menos três outras gestões iniciaram processos de debate interno e que acabaram, por diversos motivos, não sendo finalizados. Na gestão de 2010-2014 este processo iniciou somente após o debate em torno do projeto institucional - que também demandou tempo - e só foi consolidado em 2018, já na gestão seguinte.

Mais do que uma suposta morosidade, nossa avaliação é que o tempo dilatado tem a ver justamente com a centralidade desta discussão para a comunidade do Setor de Educação, além da opção pelo método do debate aberto e participativo. Ou seja, o debate em torno do regimento não foi tratado como uma mera questão burocrática, mas como um tema de relevância teórico-prática para toda a comunidade.

O processo que iniciou em 2013, passou por várias comissões sistematizadoras, inúmeros debates por categorias, assembleias setoriais para ao final ser aprovado no Conselho Setorial e encaminhado para aprovação no Conselho de Planejamento e Administração da UFPR.

É o que descreve sumariamente o documento da direção do Setor que encaminha o processo à Secretaria de Órgãos Colegiados da UFPR, em setembro de 2018:

Esclarecemos, de partida, que a presente proposta vai ao encontro de um anseio de algumas décadas desta comunidade setorial, considerando que o regimento ainda vigente do Setor data da década de 1970.

Nesse sentido, tem-se registradas iniciativas para atualização do seu texto em períodos anteriores ao ano de 2010 - sem que se tenha conseguido, em termos práticos, avançar na concretização de uma proposta.

Em 22 de abril de 2013 - por meio da portaria Portaria no 017/13 - ED, que nomeou representantes docentes dos três departamentos acadêmicos do Setor de Educação, além de representantes técnicos administrativos e discentes oficializou-se uma nova iniciativa para a construção de uma proposta. Após ampla discussão e construção de uma primeira versão 
de um novo regimento, a comunidade setorial, através do conselho setorial, decidiu por nomear nova comissão para tratar de mais destaques e alterações na sua redação - nomeada pela Portaria no 37/14 - ED de 15 de dezembro de 2014. Assim, uma segunda versão da proposta foi submetida à avaliação de assembleia setorial de 25 de fevereiro de 2016, aberta a participação de todos os docentes, técnicos e discentes do Setor de Educação. Nesta ocasião, contudo, ainda que se tenham registrado mais contribuições ao texto, a categoria dos técnicos administrativos solicitou a prorrogação do debate por mais tempo, para a discussão interna e contribuição à proposta de regimento. A partir de devolutiva da representação dos servidores técnicos administrativos, em agosto de 2016, realizaram-se ainda cinco sessões (15/09/2017; 05/10/2017; 09/11/2017; 16/11/2017; 13/12/2017) de discussão em reuniões abertas do conselho setorial, algumas delas convocadas exclusivamente para esta finalidade. Por fim, tendo-se dirimido todas as dúvidas quanto à proposta de novo Regimento do Setor de Educação, o mesmo foi aprovado por unanimidade (com quórum qualificado de $2 / 3$ dos membros) em reunião realizada em 22 de fevereiro de 2018. Diante deste longo histórico e da ampla discussão interna em nossa comunidade setorial, solicitamos a apreciação deste Órgão Superior da UFPR (OFÍCIO 80/2018).

Com relação à estrutura administrativa, o debate em torno da criação de uma outra unidade que substituísse os departamentos tomou grande parte do tempo, sendo proposta, numa primeira versão, a criação de núcleos, voltando-se ao final à forma atual da organização departamental. A opção pela manutenção da estrutura vigente levou em consideração, fortemente, a gestão da força de trabalho docente, o que inclui distribuição de aulas e definição de concursos que, na inexistência da estrutura de unidades sub-setoriais acabam concentradas na direção do Setor. Os argumentos favoráveis à substituição dos departamentos, por outro lado, apontavam para a necessidade de uma maior flexibilização das relações entre as áreas de conhecimento. Contudo, o entendimento majoritário foi que os núcleos de pesquisa e extensão, que foram incorporados ao regimento, dariam conta desta tarefa.

Outras mudanças administrativas visaram atualizar as funções das estruturas que foram sendo criadas e racionalizar e horizontalizar funções administrativas.

Um destaque importante foi a criação da Comissão Permanente de Gestão dos Técnicos-Administrativos, proposto pelo coletivo dos TAE, assim definida:

Art. 94 A Comissão Permanente de Gestão de Técnicos/as Administrativos/as Educacionais - CPGTAE é parte da estrutura administrativa do Setor de Educação, de forma independente e paritária, com a função de 
gerir a alocação dos/as técnicos/as no âmbito do Setor de Educação; a Programação de Capacitação e Qualificação dos/as técnicos/as no país ou fora dele; a capacitação técnica para participação preferencial dos/as técnicos/as do Setor em Projetos de Extensão e de Pesquisa em convênios com o Setor, com ampla divulgação desses processos de seleção; subsidiar as decisões acerca da remoção de técnico/as; e outros assuntos relacionados à movimentação interna, participação em projetos e qualificação (SETOR DE EDUCAÇÃO, 2016).

No caso das estruturas e mecanismos de gestão, foi incorporado o Centro de Articulação de Licenciaturas, bem como o orçamento participativo e a assembleia setorial, com função consultiva.

\section{Considerações finais: avanços, processos e desafios}

O processo de construção da gestão setorial repousa sobre os avanços herdados das gestões anteriores e o acúmulo da comunidade institucional e projeta seus horizontes para os períodos futuros.

É desejo de todo gestor e gestora comprometido com um projeto público e democrático que ações geradas no processo de seu mandato frutifiquem para além dos limites temporais do exercício do cargo.

Com a experiência teórico-prática que logramos desenvolver na gestão setorial, no espaço da universidade pública, concluímos que nem tudo dependerá da vontade ou do esforço, mas, sem dúvida, a existência de um projeto intencional e articulado de forma coletiva é fundamental para que os processos se tornem parte da instituição e não apenas da expressão personificada do exercício do poder.

Por outro lado, há limites, seja da cultura institucional, seja do contexto mais geral que facilitam ou dificultam política, cultural e economicamente determinadas ações e movimentos. Por isso, é fundamental conhecer a realidade em que se atua e só se faz isto com a parceria de muitas mãos, vozes e olhares. Não há onisciência na gestão pública, muito menos onipotência.

É preciso também permitir que processos fluam, que os profissionais sejam valorizados e que a comunidade - interna e externa - tome parte ativa do projeto público e democrático.

Contudo, fundamentalmente, é preciso não ignorar a realidade que nos cerca, entender que não há projeto de universidade e educação sem projeto de país.

É preciso atuar conjuntamente. É preciso não descuidar do futuro e da esperança. 


\section{REFERÊNCIAS}

BLOG DE CAMPANHA. Chapa Democracia: Participação, Pluralidade e Diversidade. 2010. Disponível em: http://andreadeise.blogspot.com/2010/. Acesso em: 19 dez. 2018.

BRASIL. Decreto 6986/09. Decreto no 6.986, de 20 de outubro de 2009. Disponível em: https://presrepublica.jusbrasil.com.br/legislacao/819716/decreto-6986-09. Acesso em: 19 dez. 2018.

BRASIL. Lei no 9.192, de 21 de dezembro de 1995. Disponível em: http://www.planalto. gov.br/ccivil_03/leis/19192.htm. Acesso em: 19 dez. 2018.

SETOR DE EDUCAÇÃO. Comissão Permanente de Gestão dos Técnicos-Administrativos. Plano de Qualificação para os Servidores Técnico Administrativos em Educação lotados no Setor de Educação da UFPR. 2016. Disponível em: http://www.educacao. ufpr.br/portal/wp-content/uploads/2016/05/Plano_qualificacao_TAEsED_oficial.pdf. Acesso em: 19 dez. 2018.

SETOR DE EDUCAÇÃO. Memorial do Setor de Educação. Disponível em: http://www. educacao.ufpr.br/portal/memorial/. Acesso em: $19 \mathrm{dez} 2018$.

SETOR DE EDUCAÇÃO. Planejamento Institucional. 2013. Disponível em:http://www. educacao.ufpr.br/portal/wp-content/uploads/2013/03/projeto-institucional-pos-revisao. pdf. Acesso em: 19 dez. 2018.

UFPR. Atas publicadas na página do Setor de Educação. Disponível em: http://www. educacao.ufpr.br/portal/conselho-setorial. Acesso em: 19 dez. 2018.

UFPR. Resolução 35/17-CEPE. Disponível em: http://www.soc.ufpr.br/portal/wp-content/uploads/2017/12/cepe3517assinada.pdf. Acesso em: 19 dez. 2018.

UFPR. Regimento do CEALI publicado na página do Setor de Educação. Disponível em: http://www.educacao.ufpr.br/portal/sobre-o-ceali/. Acesso em: 19 dez. 2018.

UFPR. Reportagem publicada na página oficial da UFPR. Setor de Educação comemora o Dia D Educação. 15 de outubro de 2010. Disponível em: http://www.ufpr.br/portalufpr/ noticias/setor-de-educacao-comemora-o-dia-d-educacao/. Acesso em: 19 dez. 2018.

UFPR. Reportagem publicada na página oficial da UFPR. "Dia D Educação" reflete sobre a Base Nacional Comum Curricular do Ensino Médio - 15 de outubro. Disponível em: http://www.ufpr.br/portalufpr/eventos/dia-d-educacao-reflete-sobre-a-base-nacional-comum-curricular-do-ensino-medio-15-de-outubro/. Acesso em: 19 dez. 2018.

Texto recebido em 09 de maio de 2019.

Texto aprovado em 29 de maio de 2019. 